\title{
A Study on the Dynamic Relationship Between Industrial Agglomeration and Technological Innovation in Chengdu Economic Zone*
}

\author{
Lu Zhou \\ Sichuan College of Architectural Technology \\ Deyang, China 618000
}

\begin{abstract}
Based on the statistical data of industrial agglomeration and technological innovation in Chengdu Economic Zone from 2005 to 2016, the dynamic relationship between industrial agglomeration and technological innovation is studied by using dynamic panel data model. The results show that industrial agglomeration promotes the development of technological innovation. There is obvious lag effect between the two, the level of economic development, the level of urbanization, the level of fixed asset investment and $R \& D$ costs are related to technological innovation, but there are obvious differences between different industries.
\end{abstract}

Keywords-Chengdu Economic Zone; industrial agglomeration; technological innovation; dynamic panel data model

\section{INTRODUCTION}

Chengdu Economic Zone is the region with the largest economic aggregate and the highest level of social and economic development in Sichuan Province. In 2016, the regional GDP of Chengdu Economic Zone was 2,077.41 billion yuan, an increase of $8.6 \%$ over the same period of last year and 0.9 percentage points higher than the average level of Sichuan Province. With the expansion of economic activities, related industries have gathered in a certain area of Chengdu Economic Zone. The spillover effect of industrial agglomeration promotes the improvement of economic efficiency. Industrial agglomeration can influence technological innovation capability through new knowledge and new technology, while the technological innovation is an important way for Chengdu Economic Zone to improve the quality of economic growth, and technological innovation has shown a concentrated situation in geographical location. Therefore, studying the relationship between industrial agglomeration and technological innovation in Chengdu Economic Zone has important practical significance for further developing industrial agglomeration and promoting technological innovation.

*Fund Project: Deyang City Social Science Research Planning Project in 2018: "Research on the Dynamic Relationship between Industrial Agglomeration and Technological Innovation in Chengdu Economic Zone" (Project Number: DY18C018)

\section{LITERATURE REVIEW}

The original study of industrial agglomeration and innovation is related to Alfred Marshall, founder of classical economics. Marshall (1920) [1] believes that industrial agglomeration is mainly caused by factors such as labor market sharing, intermediate product input and technology spillovers. Industrial agglomeration is conducive to the dissemination and application of new ideas, new knowledge and new skills in specific regions. Lynn Mytelka and Fulvia Farinelli (2000) [2] analyzed the relationship between the types of industrial agglomerations and technological innovations, and found that there are significant differences in the innovation activities of different types of industrial agglomeration enterprises; Storper and Venables' (2004) [3] studies show that industrial agglomeration can provide convenient face-to-face communication opportunities to promote knowledge spillovers.

Chinese scholars have also conducted a more detailed study on the issues of industrial agglomeration and technological innovation. Zhang Jie, Liu Zhiwei and Zheng Jianghuai (2007) [4] used the influence of Jiangsu manufacturing data research industry agglomeration on the innovation intensity of enterprises, and found that the agglomeration effect did not have a positive impact on the innovation activities of Chinese enterprises, and had not become an organic carrier to stimulate cluster innovation; Du Jiang, Zhang Weike and Ge Yao (2017) [5] examined whether there would be a threshold effect and spatial effect on the impact of industrial agglomeration on regional technological innovation. The study found that the impact of industrial agglomeration on regional technological innovation is nonlinear and U-shaped.

According to the research of comprehensive scholars, the research on industrial agglomeration and technological innovation has not reached a consistent conclusion, and the research perspective mostly focuses on the impact of hightech industry agglomeration on technological innovation. However, even if the conclusion that high-tech industry agglomeration promotes technological innovation is established, due to the large differences in resource endowments, regional conditions, industrial bases, and institutional environments, it is difficult to achieve the 
expected results without considering regional specific conditions. In view of this, this paper studies whether industrial agglomeration promotes technological innovation according to the economic development level and conditions of Chengdu Economic Zone, and provides theoretical support for the cultivation of industrial clusters in Chengdu Economic Zone to promote technological innovation.

\section{EMPIRICAL ANALYSIS OF INDUSTRIAL AGGLOMERATION AND TECHNOLOGICAL INNOVATION}

There are many factors influencing the technological innovation of Chengdu Economic Zone, and industrial agglomeration is only one of the important influencing factors. This section uses the statistical data of Chengdu Economic Zone from 2005 to 2016. Through the establishment of the panel dynamic model, this paper attempts to analyze the interaction between industrial agglomeration and technological innovation in Chengdu Economic Zone from a dynamic perspective, in order to reveal the dynamic relationship between industrial agglomeration and technological innovation in Chengdu Economic Zone, and provide reference for further optimizing the economic development mode of Chengdu Economic Zone.

\section{A. Model Establishment and Variable Selection}

In order to analyze the regional differences in Chengdu economic zone and other variables in the specific impact of industrial agglomeration in the process of enterprise technology innovation, this paper establishes the following basic measurement models:

$$
\begin{gathered}
\text { inno }_{i, t}=a+b_{1} \text { clus }_{i, t-1}+\stackrel{\circ}{\mathrm{a}} b_{j} \text { ctrl }_{i t}+l_{i}+e_{i, t} \\
(i=1,2, \ldots, N ; t=1,2, \ldots, T)
\end{gathered}
$$

inno $_{i t}$ in the model is the explanatory variable. According to the needs of data analysis and the availability of data, inno $_{\text {it }}$ is represented by the number of patent grants in Chengdu Economic Zone. This is mainly because with the improvement of the degree of intellectual property protection in China, patent holders actively apply for patents in order to protect and use their own intellectual property more effectively. That is to say, the number of patent grants reflects the actual situation of technological innovation.

The industrial agglomeration index $\left(c l u s_{i t}\right)$ is an explanatory variable. At present, the measurement of industrial agglomeration mainly includes location entropy, regional concentration index, Herfindahl index, Lorenz curve, spatial Gini coefficient, dynamic agglomeration index and so on. This paper mainly studies the influence of industrial agglomeration on technological innovation. Therefore, the measurement method of industrial agglomeration mainly draws on the measurement methods proposed by Zhang Xiaodi and Wang Yongqi (2010) [6]:

$$
\text { cluster }_{i}=\frac{1}{24} \sum_{j}^{24} X_{i j}, X_{i j}=\frac{i \text { region } j \text { industry industrial production value } / i \text { region's GDP }}{\sqrt{\text { National } j \text { industry industrial production value / national GDP }}}
$$

$X_{i j}$ is a reflection of the degree of comparative advantage of $i$ area in the $j$ industry, that is, the location entropy index. The larger the indicator value of the usual situation, the higher the degree of industrial agglomeration in the region. Although this paper adopts the measurement methods of Zhang Xiaodi and Wang Yongqi (2010), it also makes some modifications according to the characteristics and needs of the research questions. According to the national statistical indicators, the industry is divided into three industries, so cluster $_{i}=\frac{1}{3} \sum_{j}^{3} X_{i j}$, and the others stay the same.

According to theoretical research and existing research results, this paper adds other control variables that affect technological innovation in the model:

1) $R \& D$ expenditure internal expenditure level ( $r d f)$ : The investment in technological innovation is mainly for R\&D capital investment and researcher input. Industrial agglomeration often leads to an increase in $R \& D$ expenses, which in turn increases the level of technological innovation which in this paper is represented by the proportion of the total internal expenditure of $R \& D$ expenditure accounting for GDP.

2) Economic development level (edl): The level of economic development directly affects the industrial agglomeration process and also affects the level of R\&D investment. This paper measures the level of economic development by per capita GDP.

3) The level of fixed assets investment (fai): The level of fixed assets investment reflects the regional production capacity and operational capacity. The proportion of total fixed assets investment in GDP is used as a proxy.

4) Urbanization level (cdl):This paper uses the urbanization rate of Chengdu Economic Zone to express the status of urban development.

Considering the hysteresis of inertia and spillover effects of technological innovation and industrial agglomeration in Chengdu Economic Zone, and the nonlinear and complex effects of different influencing factors on technological innovation, this paper proposes a standard model based on formula (1) for analyzing technological innovation and industrial agglomeration as follows: 


$$
\begin{aligned}
\text { inno }_{i t} & =\alpha+\beta_{1} \text { inno }_{i t-1}+\beta_{2} \text { clus }_{i t}+\beta_{3} \text { clus }_{i t-1}+\beta_{4} \text { clus }_{i t} * i n n o_{i t}+\beta_{5} r d f_{i t} \\
& +\beta_{6} e d l_{i t}+\beta_{7} \text { fai }_{i t}+\beta_{8} c d l_{i t}+\varepsilon_{i t}
\end{aligned}
$$

\section{B. Data Sources}

This paper selects the statistics of Chengdu Economic Zone from 2005 to 2016 . The industries are the 19 industries according to the 2003 statistical indicators. The data comes from the "Sichuan Statistical Yearbook", "City Economic and Statistical Yearbook of Chengdu Economic Zone and Social Economic Development Bulletin", and "City and State Patent Statistics" of Sichuan Intellectual Property Office. Data for individual missing data is supplemented by linear interpolation.

\section{Empirical Results and Analysis}

The systematic GMM estimation method is used to explore the dynamic relationship between technological innovation and industrial agglomeration in Chengdu Economic Zone, and control variables are alternately added in the process of analysis, in order to observe the effect caused by variable changes. The related measurement operations are mainly carried out in the stata14.0 software and the results are shown in "Table I".

\begin{tabular}{|c|c|c|c|c|c|c|}
\hline Variables & Model 1 & Model 2 & Model 3 & Model 4 & Model 5 & Model 6 \\
\hline \multirow[t]{2}{*}{ L.inno } & $0.964 * * *$ & $0.864 * * *$ & $0.882 *$ & 5.007 & 1.059 & $1.463^{*}$ \\
\hline & $(0.046)$ & $(0.043)$ & $(0.353)$ & $(3.545)$ & $(1.184)$ & $(0.523)$ \\
\hline \multirow[t]{2}{*}{ clus } & 0.045 & -0.111 & -0.009 & 0.576 & -0.052 & 0.000 \\
\hline & $(0.481)$ & $(0.316)$ & $(0.794)$ & $(0.001)$ & $(0.461)$ & $(0.001)$ \\
\hline \multirow[t]{2}{*}{ L.clus } & -0.016 & 0.447 & 0.132 & 2.875 & 0.514 & $0.769^{*}$ \\
\hline & $(0.415)$ & $(0.327)$ & $(0.461)$ & (1.947) & (0.694) & $(0.315)$ \\
\hline \multirow[t]{2}{*}{$\operatorname{cin}$} & & $-0.001 *$ & -0.000 & -0.003 & -0.001 & $-0.001 *$ \\
\hline & & $(0.000)$ & $(0.000)$ & $(0.002)$ & $(0.001)$ & $(0.000)$ \\
\hline \multirow[t]{2}{*}{$c d l$} & & & 0.010 & -0.285 & -0.047 & -0.076 \\
\hline & & & $(0.074)$ & $(0.264)$ & $(0.146)$ & $(0.055)$ \\
\hline \multirow[t]{2}{*}{ edl } & & & & -6.529 & -0.050 & -0.679 \\
\hline & & & & $(5.258)$ & $(2.040)$ & $(0.931)$ \\
\hline \multirow[t]{2}{*}{$r d f$} & & & & & 0.255 & $0.230 *$ \\
\hline & & & & & $(0.235)$ & (0.090) \\
\hline \multirow[t]{2}{*}{$f a i$} & & & & & & 0.009 \\
\hline & & & & & & $(-0.036)$ \\
\hline \multirow[t]{2}{*}{ _cons } & 0.448 & 0.790 & 0.452 & 49.557 & 1.560 & 6.250 \\
\hline & $(0.731)$ & $(0.509)$ & $(1.921)$ & (39.971) & (15.458) & (6.906) \\
\hline
\end{tabular}

TABLE I. GMM REgRESSION RESULTS OF INDUSTRIAL AGGLOMERATION AND TECHNOLOGICAL INNOVATION IN CHENGDU ECONOMIC ZONE

a. Note: $* * *, * *$, indicates significant improvement at the $1 \%, 5 \%$, and $10 \%$ levels. What in the brackets are standard errors.

"Table I" is based on the regression results of the entire industry in the Chengdu Economic Zone. The 2nd column is the analysis of the relationship between technological innovation and industrial agglomeration without considering other control variables. The results show that technological innovation has a significant lag effect, and industrial agglomeration promotes technological innovation. But the effect of the impact is not significant. The industrial agglomeration index of the lagging first phase impedes its previous technological innovation, which indicates that the effect of industrial agglomeration is attenuated to a certain extent. From the 3rd column to the 7th column of "Table I", they are the interactive items that gradually increase the number of control variables and the core variables in the basic model. The empirical results show that the impact of technological innovation and industrial agglomeration interactions on technological innovation shows a negative impact. Moreover, it appears to be statistically significant at a $10 \%$ significant level. The synergy effect between technological innovation and industrial agglomeration largely changes the direction and size of the impact of single industry agglomeration index on technological innovation. In addition, the two indicators of urbanization and economic development have different degrees of negative impact on the impact of technological innovation in the results of the entire regression analysis, and this effect is not significant at any significant level. This situation contradicts the forecast results. The reason may be that the urban level of Chengdu Economic Zone is low; the economic development zone is seriously unbalanced; and the external environment and technological innovation requirements have major problems. For the level of fixed assets input, it has a promoting effect on technological innovation, but the effect is not significant in statistical analysis. From the overall results, only the firstorder lag term of technological innovation in Model 1 and 
Model 2 significantly affects the technological innovation index at a significant level of $1 \%$.

\section{CONCLUSION AND POLICY RECOMMENDATIONS}

This paper selects the panel data of Chengdu Economic Zone from 2005 to 2016, and builds a dynamic panel model to study the dynamic relationship between industrial agglomeration and technological innovation.

\section{A. Conclusion}

The main conclusions are as follows: First, the industrial agglomeration of Chengdu Economic Zone promotes technological innovation, and this effect is different due to different industries. Second, the relationship between economic and industrial agglomeration and technological innovation in Chengdu is affected by other control variables. The types and numbers of variables will change the direction and size of industrial agglomeration on technological innovation to a certain extent. Third, there is a lagging effect on industrial agglomeration and technological innovation in Chengdu Economic Zone. The lag effect of technological innovation in service industry is relatively obvious, and it is remarkable at a significant level of $10 \%$. The hysteresis effect of industrial agglomeration is not outstanding, and in some cases this effect is negative.

\section{B. Policy Recommendations}

In view of the above results, it is believed that the relationship between industrial agglomeration and technological innovation in Chengdu Economic Zone should be optimized from the following aspects:

- Each region of the Chengdu Economic Zone should use its own regional advantages to determine its own advantageous industries, integrate resources and rational division of industries, accelerate the upgrading of industrial structure, and foster a competitive industrial cluster with market orientation.

- It is necessary to strengthen the modern infrastructure and informatization construction of communication, network and patent databases in industrial agglomeration areas, promote the better diffusion of scientific and technological achievements and technological innovations, encourage enterprises to set up R\&D institutions, increase investment in research and development, and improve the level of innovation of enterprises.

- Government departments should formulate relevant policies to solve the problem of technology spillovers involving intellectual property protection and promote technological innovation capabilities within industrial agglomeration.

\section{REFERENCES}

[1] Alfred Marshall, Principles of Economics [M] Lian Yunjie, trans. Beijing: Huaxia Publishing House, 2005. (in Chinese)
[2] Zhang Xinnian, Review on the Research Trends of Industrial Clusters in China and Overseas [J] Science \& Technology and Economy, 2007 (05): 16 - 19. (in Chinese)

[3] Paul Porthey, Public Policy on Environmental Protection [M] Shanghai: Shanghai People's Publishing House, 1998. (in Chinese)

[4] Zhang Jie, Liu Zhibiao, Zheng Jianghuai, Industrial Chain Positioning, Divide, Agglomeration and Innovation: An Empirical Study Based on Questionnaire of Manufacturing Firms in Jiangsu Province [J] The Journal of World Economy, 2007 (07): 47 - 55. (in Chinese)

[5] Du Jiang, Zhang Weike, Ge Yao, The Double Characteristics Analysis of Industrial Agglomeration on Technological Innovation [J] Soft Science, 2017 (11): 1 - 5. (in Chinese)

[6] Zhang Xiaodi, Wang Yongqi, Entrepreneur Appearance and Industrial Agglomeration: The Connection Effect of Financia Markets [J] China's Industrial Economics, 2010 (5): 59 - 68. (in Chinese) 